\title{
ESTABLISHING THE RELATIONSHIP BETWEEN DAMAGE MEASURE, SEISMIC HAZARD, STRUCTURAL DUCTILITY AND PERIOD FOR PBSD
}

\author{
Tai-Hsin Wen and Chin-Hsiung Loh*
}

\begin{abstract}
The goal of this research is to establish a relationship between design level and performance level. Designers can take advantage of this relationship to determine the annual probability of exceeding the seismic hazard safety level and the performance of a building subjected to a certain intensity of earthquake loading. In this research, the design level is defined by annual probability of occurrence and the performance level is presented by Park \& Ang's damage index which includes both hysteretic energy and deformation of structural response. The $\gamma$ spectrum, which considers the inelastic hysteretic energy of a nonlinear SDOF system, was developed from Taiwan ground motion data and added to the damage index. The damage spectrum, representing the design level versus annual probability of the index tolerance being exceeded, is provided in this research. Engineers can refer to these diagrams and spectra to assess if the proposed design and performance level are acceptable. An example is also made showing how to use this approach at the end of this study.
\end{abstract}

Key Words: performance-based design, seismic hazard analysis, inelastic response spectrum.

\section{INTRODUCTION}

In Vision-2000, as shown in Fig. 1, the seismic performance level of a structural system can be divided into five categories:

a. Fully operational

b. Operational

c. Life safe

d. Near collapse

e. Collapse

Each category can be related to a different degree of structure damage. The description of these levels of damage is determined by means of transient and permanent drift, as shown in Table 1, and drift is the only criteria of damage description. Besides the performance of a structure, the seismic hazard at a given site is represented as a set of earthquake ground motions and the associated recurrence interval with

*Corresponding author. (Tel: 886-2-27326607; Fax: 886-2 27322223; Email: lohc0220@ccms.ntu.edu.tw)

The authors are with the Department of Civil Engineering, National Taiwan University, Taipei, Taiwan 106, R.O.C. specific probability of index tolerance being exceeded, as shown in Table 2. There is no direct link between the seismic hazard level and the structural performance. The Vision-2000 recommended three Performance objectives at different performance levels and earthquake intensities, including basic, essential/hazardous and safety/critical objectives. The basic objective is defined as the minimum acceptable performance objective for a typical new buildings, while essential/hazardous facility and safety critical objectives are defined as the minimum objectives for facilities such as hospitals and nuclear material processing facilities, respectively.

Instead of using drift to represent structural performance, a damage index can also be used to determine the performance level. In Park and Ang's damage index, not only the displacement (ductility), but also hysteretic energy are considered (Park and Ang, 1985). It is defined as:

$$
D M=\frac{\delta_{m}}{\delta_{u}}+\frac{\beta}{Q_{y} \delta_{u}} \int d E
$$

where 
Table 1 General damage descriptions by performance levels and systems (Structural Engineers Association of California, 1995)

\begin{tabular}{lccccc}
\hline \multirow{2}{*}{$\begin{array}{c}\text { System } \\
\text { description }\end{array}$} & $\begin{array}{c}\text { Fully } \\
\text { operational }\end{array}$ & Operational & Life safe & $\begin{array}{c}\text { Near } \\
\text { collapse }\end{array}$ & Collapse \\
\cline { 2 - 5 } $\begin{array}{l}\text { Overall building } \\
\text { damage }\end{array}$ & Negligible & Light & Moderate & Severe & Complete \\
$\begin{array}{l}\text { Permissible } \\
\text { transient drift }\end{array}$ & $<0.2 \%$ & $<0.5 \%$ & $<1.5 \%$ & $<2.5 \%$ & $>2.5 \%$ \\
$\begin{array}{l}\text { Permissible } \\
\text { permanent drift }\end{array}$ & Negligible & Negligible & $<0.5 \%$ & $<2.5 \%$ & $>2.5 \%$ \\
\hline
\end{tabular}

Table 2 Probability of failure associated seismic hazard (Structural Engineers Association of California, 1995)

\begin{tabular}{lcc}
\hline Event & Recurrence interval & Probability of failure \\
\hline Frequent & 43 years & $50 \%$ in 30 years \\
Occasional & 72 years & $50 \%$ in 50 years \\
Rare & 475 years & $10 \%$ in 50 years \\
Very rare & 970 years & $10 \%$ in 100 years \\
\hline
\end{tabular}

\begin{tabular}{|l|l|}
$\begin{array}{l}\text { Damage range \& } \\
\text { damage index }\end{array}$ & $\begin{array}{l}\text { No damage, continuous service } \\
\text { Continuous service, facility operates and functions } \\
\text { after earthquake. Negligible structural and } \\
\text { nonstructural damage. }\end{array}$ \\
\hline $\begin{array}{l}\text { Most operations and functions can resume } \\
\text { immediately. Repair is required to restore some } \\
\text { non-essential services. Damage is light. } \\
\text { Sturcture is safe for occupancy immediately after } \\
\text { earthquake. Essential operations are protected, } \\
\text { nonessential operations are disrupted. }\end{array}$ \\
\hline $\begin{array}{ll}\text { Damage is moderate. Selected building systems, } \\
\text { features or contents may be protected from damage. }\end{array}$ \\
\hline $\begin{array}{l}\text { Life safety is generally protected. Structure is damages } \\
\text { but remains stable. Falling hazards remain. }\end{array}$
\end{tabular}

Fig. 1 Spectrum of seismic damage states (Structural Engineers Association of California, 1995)

$d E=$ incremental dissipated hysteretic energy

$\delta_{m}=$ maximum deformation

$\delta_{u}=$ ultimate deformation capacity under mono- tonic loading

$Q_{y}=$ yield strength

$\beta=$ non-negative constant 
To improve the literature description of Vision2000 on performance levels, Park \& Ang's damage index can be proposed to describe the performance level. Therefore, this research is trying to develop the relationship between the seismic hazard, in terms of the annual probability of index tolerance being exceeded and the structural damage level. This result can allow engineers to choose a specific earthquake hazard under the requirement of the performance level.

In the beginning, the damage index associated with the four performance levels should be assumed. In this study, these four performance levels are represented by damage indices $(D M)$ which can be categorized into four levels, i.e. $D M=0.25,0.5,0.75$, and 1.0, respectively. These four levels of damage index do not correlate with the associated earthquake recurrence intervals, which are represented as 43,72 , 475 and 970 year return periods (as shown in Table 2 ), because the probability of index tolerance being exceeded is only generated by seismic hazard analysis, such as the characteristics of ground motions, earthquake magnitude and hypocenter distance etc.

In this research, the relationship between design level (probability of index tolerance being exceeded represented) and performance level (damage index represented) is established. It will provide engineers a reference to design a structure meeting specific performance and design levels. The basic objectives, the annual probability of index tolerance being exceeded associated to the 4 performance levels (fully operational with $1 / 43$ probability of tolerance being exceeded, operational with $1 / 72$ probability of tolerance being exceeded, life safe with $1 / 475$ probability of tolerance being exceeded, and near collapse with $1 / 970$ probability of tolerance being exceeded) are discussed. Finally, the damage indices $(D M=0.25$, $0.5,0.75,1.0)$ are used to determined these four performance levels. The associated annual probability of tolerance being exceeded are no longer fixed to $1 / 43,1 / 72,1 / 475,1 / 970$, respectively. The structural performance level is related to system characteristics.

\section{HYSTERETIC ENERGY PARAMETER $-\gamma$ SPECTRUM}

In Vision-2000 (Structural Engineers Association of California, 1995), the drift is the main parameter to define the performance level. Instead of drift, Park \& Ang's damage index can also provide a parameter to define the performance level. By using Park \& Ang's damage index, both ductility and hysteretic energy must be considered, since ductility is related to maximum displacement, and the inelastic displacement spectra can provide this information
(Miranda and Ruiz-Garcia, 2002). As for the hysteretic energy, a more detailed study is needed. Because a damage index is related to the hysteretic energy and displacement for the structure system, the predictive procedure for hysteretic energy will be proposed in this study.

An important non-dimensional parameter, $\gamma$, is defined as (Vidic et al., 1994a) :

$$
\gamma=\frac{\sqrt{\frac{E h}{m}}}{\omega D}
$$

where $E_{h}$ is the dissipated hysteretic energy, $m$ is the mass of the system, $\omega$ is the natural frequency and $D$ is the maximum relative displacement of the system. According to Fajfar's study (Vidic et al., 1994a), the $\gamma$-spectrum can be divided into three terms (P-F model):

$$
\gamma=z_{T} z_{\mu} z_{g}
$$

where

$$
\begin{aligned}
& z_{T}=0.9-0.25 \frac{T-T_{1}}{T_{2}-T_{1}} \\
& z_{\mu}=\frac{(\mu-1)^{C_{\mu}}}{\mu} \\
& z_{g}=\left(\frac{I_{e}}{P G A \cdot P G V}\right) C_{g}
\end{aligned}
$$

where $I_{e}$ is the integral of the squared ground acceleration, and $C_{g}=0.4, \mathrm{C}_{\mu}=0.7$ are provided in the case of the bilinear model and mass-proportional damping. $T_{1}, T_{2}$ represent the separation points among the short-, medium- and long-period regions of the elastic response spectrum. In addition, they can also be estimated by the equations as follows:

$$
T_{1}=2 \pi \frac{c_{v} \cdot P G V}{c_{a} \cdot P G A} ; T_{2}=2 \pi \frac{c_{d} \cdot P G D}{c_{a} \cdot P G V}
$$

where $c_{v}, c_{d}, c_{a}$ were determined by a trial-and-error procedure for all the investigated groups of records (Vidic, 1994b).

To verify the proposed $\gamma$-spectrum of the P-F model using Taiwan records, a SDOF system with bilinear hysteretic model is used for analysis (with ductility $\mu=2,4$, and 6 ). Seventy ground motion records of Taiwan (normalized to the $P G V=0.5$ $\mathrm{m} / \mathrm{sec}$ ) were selected. The hysteretic energy $\left(E_{h}\right)$ and maximum displacement $(D)$ of the inelastic SDOF system are developed (Uang \& Bertero, 1990). Comparison on the $\gamma$-spectrum between the P-F model and the exact data is shown in Fig. 2. Good agreement between the P-F model and the generated $\gamma$-spectrum is consistent. 


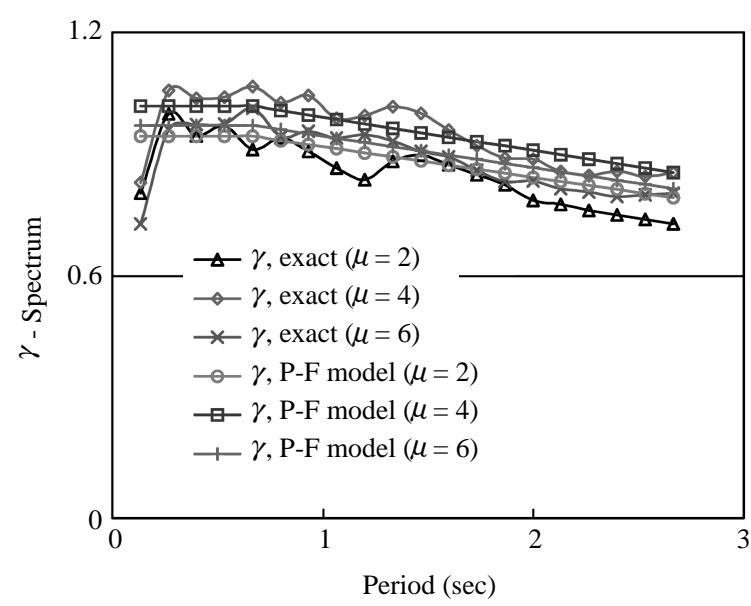

Fig. 2 Comparison of $\gamma$ spectrum between "exact" and P-F model

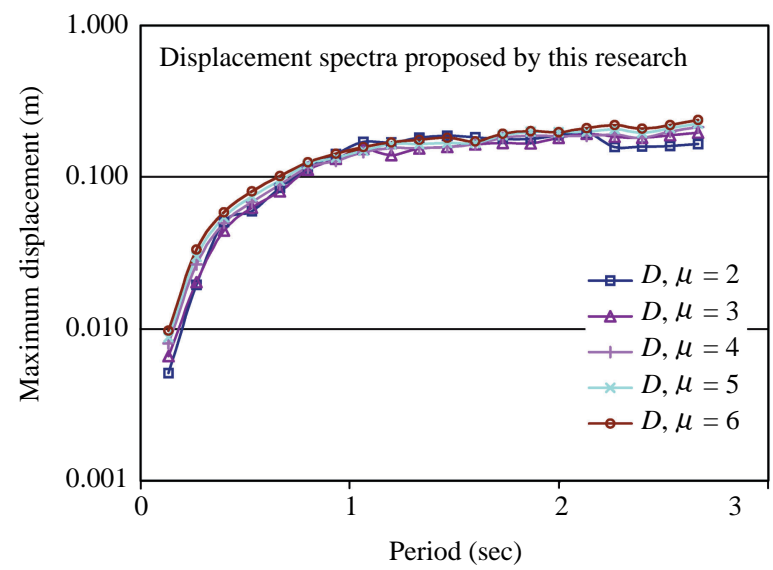

Fig. 3 The relative displacement spectra proposed by this research (the maximum velocity of input ground motion is normalized to $0.5 \mathrm{~m} / \mathrm{sec}$ )

\section{PREDICTION OF HYSTERETIC ENERGY}

The relationship between hysteretic energy, $E_{h}$, and the $\gamma$-spectrum (as shown in Eq. (2)) can be rewritten as follows (Vidic, 1994a):

$$
\frac{E h}{m}=(\gamma \cdot \omega \cdot D)^{2}
$$

From Eq. (8), the hysteretic energy of the basic system can be predicted if $\gamma$-spectrum and maximum relative displacement spectra $(D)$ are provided. With the same selected 70 ground motion records, the inelastic displacement spectra can also be generated (damping ratio $\zeta=0.05$, EPP model), as shown in Fig. 3. Comparison on Miranda's approximate method for estimating maximum inelastic displacement demands, Fig. 4 is generated too. These two inelastic displacement spectra correlate quite well. Therefore, by using a simplifying regression equation,

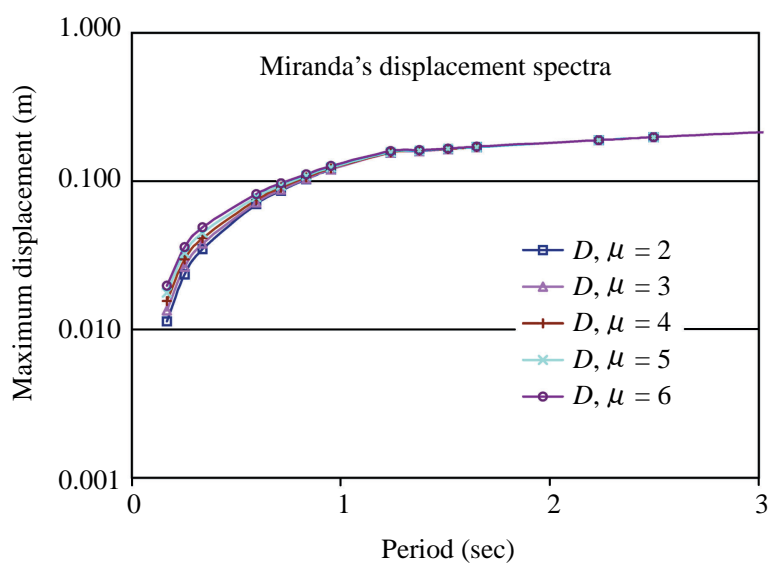

Fig. 4 The relative displacement spectra recommended by Miranda for various ductility demands (the maximum velocity of input ground motion is normalized to $0.5 \mathrm{~m} / \mathrm{sec}$ )

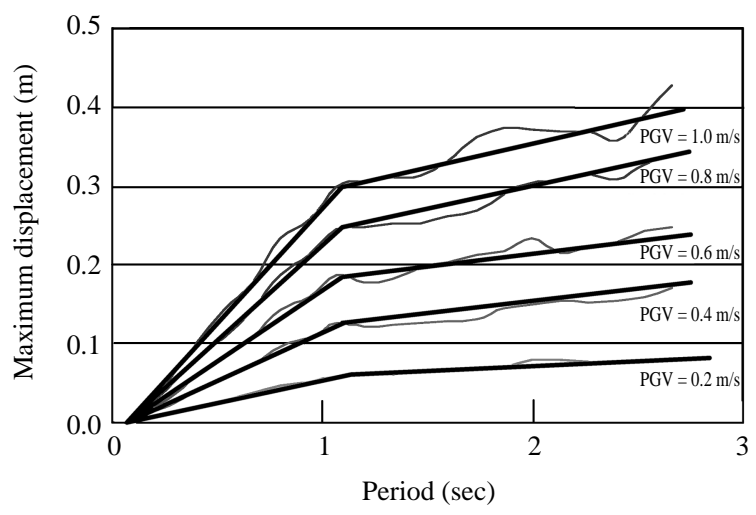

Fig. 5 Relative inelastic displacement spectra for different intensity levels $(P G V=0.2 \sim 1.0 \mathrm{~m} / \mathrm{s})$ at $\zeta=0.05$ with 70 ground motion records in Taiwan

a prediction of inelastic displacement spectra is proposed (with $\zeta=0.05$ and EPP model) without regarding the minor influence of ductility, as shown in Eq. (9), and the displacement spectra is shown in Fig. 5.

$$
\begin{aligned}
& \left.\begin{array}{ll}
D=(0.228+0.0665 \cdot T) \cdot P G V & \text { as } T>1.2 s \\
D=0.28 \cdot(T-0.1) \cdot P G V & \text { as } 0.1<T<1.2 s
\end{array}\right\} \\
& =D_{n}(T) \cdot P G V
\end{aligned}
$$

where $T$ is period of the system, $P G V$ is the peak velocity of ground motion, and

$$
\begin{array}{ll}
D_{n}(T)=(0.228+0.0665 \cdot T) & \text { as } T>1.2 s \\
D_{n}(T)=0.28 \cdot(T-0.1) & \text { as } 0.1<T<1.2 s
\end{array}
$$

Equation (3) and Eq. (9) provide theoretical models on the estimation of $\gamma$-spectrum and the 
inelastic maximum displacement. Both equations can be implemented for the estimation of hysteretic energy, as shown in Eq. (8), which is called the regressive model of the hysteretic energy spectrum. Comparison of the $\mathrm{Eh} / \mathrm{m}$ spectrum between the regressive model and the exact hysteretic energy spectrum for a case where system ductility equals 4, 5, and 6 is shown in Fig. 6 (for the case of EPP model). A satisfactory agreement between the regressive and the exact hysteretic energy spectrum can be observed.

\section{SEISMIC HAZARD ANALYSIS OF HYSTERETIC ENERGY $\left(E_{h} / m\right)$}

In seismic hazard assessment of a site, the hypocenter distance, earthquake magnitude and soil condition should be considered, and then the relationship between annual probability of exceeding the index's tolerance and intensity measure can be proposed. Because the damage index is the parameter to define the performance level, seismic hazard analysis with respect to damage index should be discussed. Since the main contribution to damage index is hysteretic energy, the seismic hazard for hysteretic energy should be analyzed. From the result of hazard analysis, the designer can choose the design level according to the specific performance. For assessing the system hazard, the attenuation equation of hysteretic energy is derived.

From Eq. (3), (8), and (9), the parameters of hysteretic energy can be separated into two parts: one is in relation to system characteristics, $B(T)$, and the other is in relation to ground motion characteristics, $\varepsilon$. The hysteretic energy per unit mass can be expressed as follows:

$$
\begin{aligned}
\frac{E_{h}}{m} & =(\gamma \cdot \omega \cdot D)^{2} \\
& =\left(\left(z_{T} \cdot z_{\mu} \cdot \omega \cdot \operatorname{Dn}(T)\right)^{2} \cdot\left(z_{g} \cdot P G V\right)^{2}\right)=(B(T) \cdot \varepsilon)
\end{aligned}
$$

where $B(T)$ is a non-dimensional parameter, defined as follows:

$$
B(T)=\left(z_{T} \cdot z_{\mu} \cdot \omega \cdot \operatorname{Dn}(T)\right)^{2}
$$

the unit of $\varepsilon$ is equal to the square of velocity, defined as follows:

$$
\begin{aligned}
& \varepsilon=\left(z_{g} \cdot P G V\right)^{2}=\left(\left(\frac{I e}{P G A \cdot P G V}\right)^{C g} \cdot P G V\right)^{2} \\
& \varepsilon=\frac{I e^{2 C g} \cdot P G V^{2(1-C g)}}{P G A^{2 C g}}
\end{aligned}
$$

The attenuation form of $\varepsilon$ (ground motion characteristics) is a function of $P G A, P G V$ and $I e$,

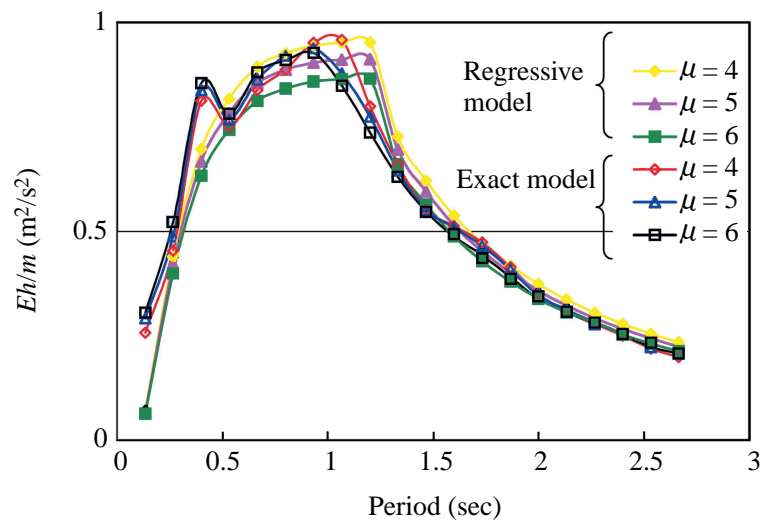

Fig. 6 Comparison of the hysteretic energy spectrum between exact and regressive models for ductility $=4,5$, and 6

and is a function of earthquake magnitude and hypocenter distance. To represent the attenuation form of $\varepsilon$, it is necessary to derive the attenuation equation for $P G A, P G V$ and $I e$.

The Campbell (Campbell, 1981) form of $P G A$ attenuation law (Loh et al., 1999) is shown below:

$$
\begin{aligned}
P G A(g)= & 0.02968 \cdot \exp [1.20 M] \cdot[R+0.1461 \\
& \cdot \exp (0.6981 M)]^{-1.7348}
\end{aligned}
$$

Using 390 ground motion records of Taiwan from 1990 to 2000, the attenuation equations for $P G V$ and $I e$ were expressed as below:

$$
\begin{aligned}
P G V(\mathrm{~m} / \mathrm{sec})= & 0.02 \cdot \exp [0.9 M] \cdot[R+0.05 \\
& \exp (0.75 M)]^{-1.15} \\
I e\left(\mathrm{~m}^{2} / \mathrm{sec}^{3}\right)= & 0.00162 \cdot \exp [2.1367 M] \\
\cdot & {[R+0.1461 \cdot \exp (0.6981 M)]^{-1.95} }
\end{aligned}
$$

Verification of the proposed attenuation form with these 390 specific ground motion records is also made. Figs. 7 9 show the comparison of the data with respect to the proposed attenuation form.

Through defining the attenuation equation for $P G A, P G V$, and $I e$ respectively, the attenuation equation for $\varepsilon$ can be derived from Eq. (14), as shown in Eq. (18) and (19).

$$
\begin{aligned}
\varepsilon\left(m^{2} / \mathrm{sec}^{2}\right)= & \frac{I e^{2 C g} \cdot P G V^{2(1-C g)}}{P G A^{2 C g}}=\frac{I e^{0.8} \cdot P G V^{1.2}}{P G A^{0.8}} \\
\varepsilon\left(\mathrm{m}^{2} / \mathrm{sec}^{2}\right)= & 0.00875 \cdot \exp (1.829 M) \cdot[R+0.056 \\
& \cdot \exp (0.7442 M)]^{-1.553}
\end{aligned}
$$




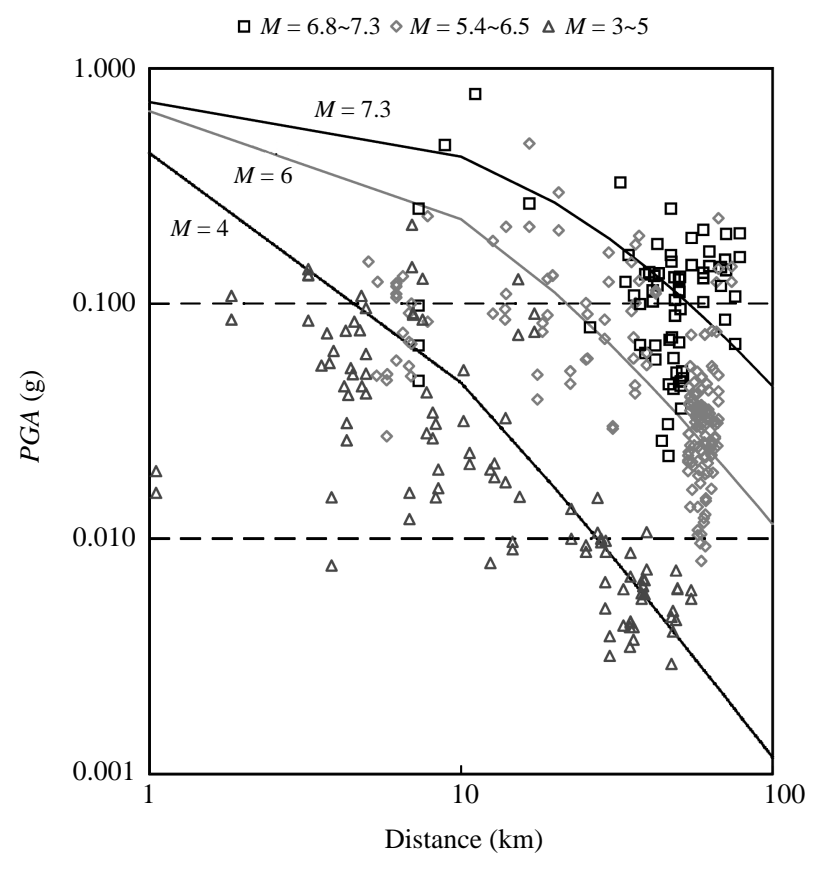

Fig. 7 Plot of the attenuation relationship of PGA. The PGA value from 390 ground motion records in Taiwan with different magnitudes and hypocenter distances is also shown.

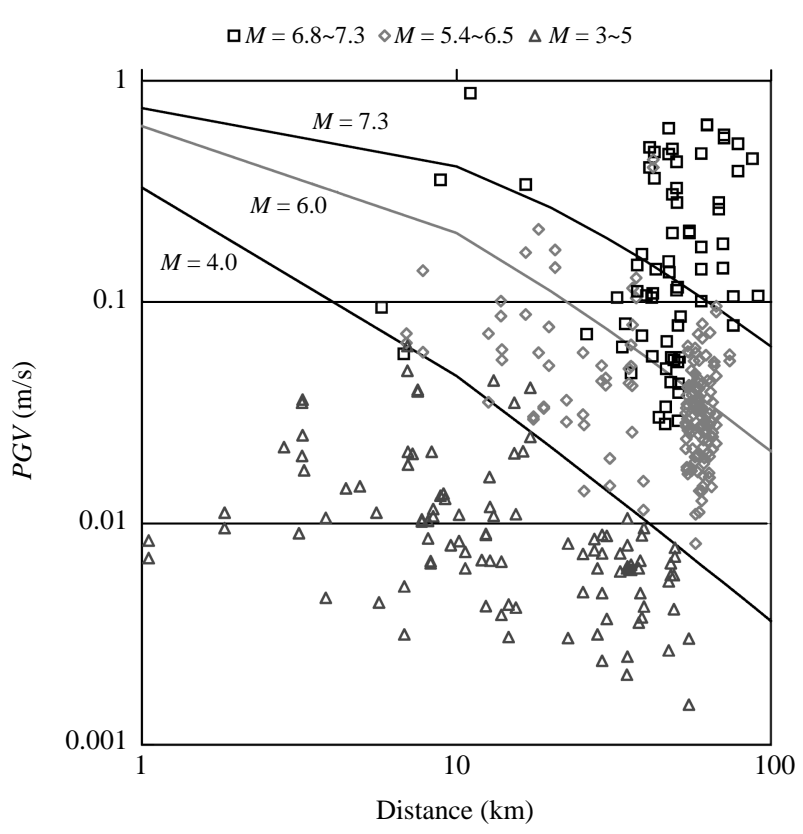

Fig. 8 Plot of the attenuation relationship of $P G V$. The $P G V$ value from 390 ground motion records in Taiwan with different magnitudes and hypocenter distances is also shown.

An example is adopted to present the result of this research. For seismic hazard analysis, the site should be specified first. I-Lan county is chosen as the site for this example. The seismic hazard analysis can be conducted with respect to the attenuation equation of $\varepsilon$. Fig. 10(a) shows the attenuation of the $\varepsilon$-curve

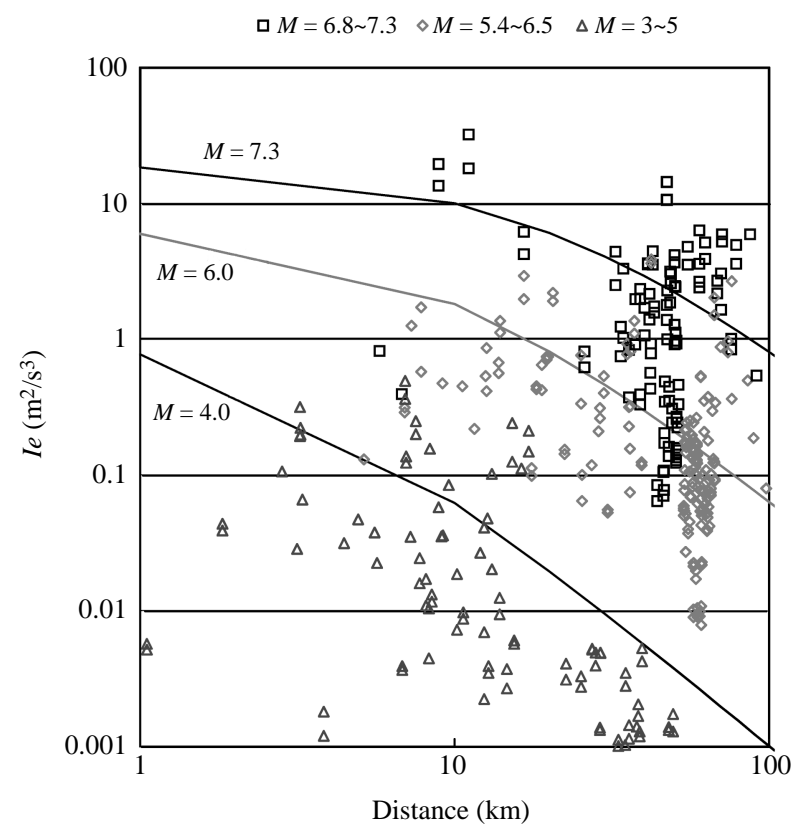

Fig. 9 Plot of the attenuation relationship of Ie. The Ie value from 390 ground motion records in Taiwan with different magnitudes and hypocenter distances is also shown.

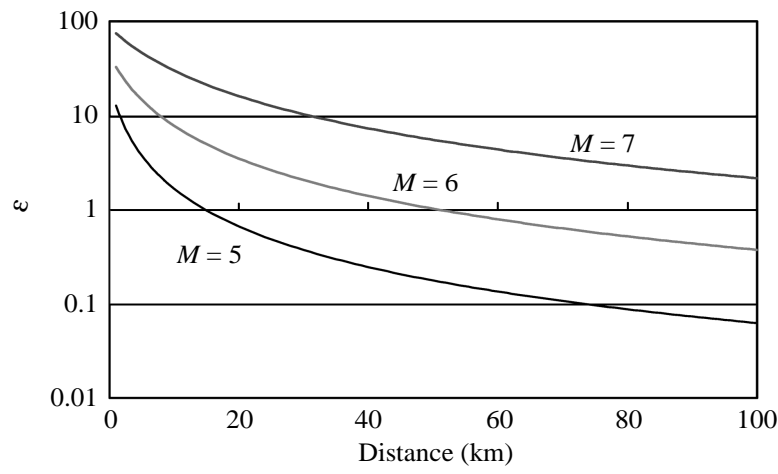

(a)

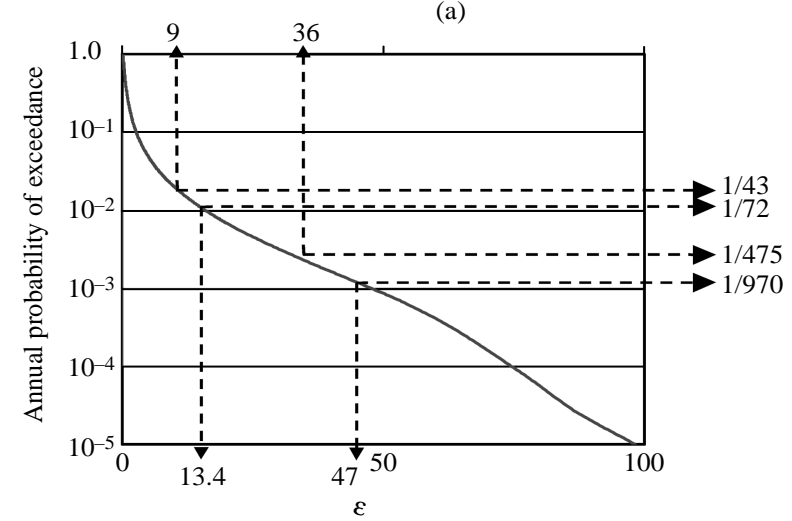

(b)

Fig. 10 (a) Plot of $\varepsilon$ with respect to distance for different magnitudes $=5,6$ and 7; (b) Seismic hazard curve of $\varepsilon$ of I-Lan county

with respect to distance for different magnitudes, 5, 6 and 7, respectively. According to the recommendation of Vision-2000, the annual probabilities of 


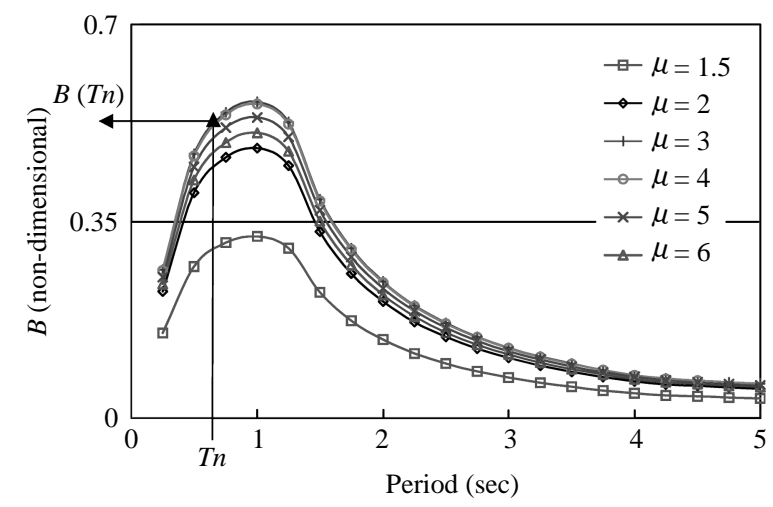

Fig. 11 Plot of $B(T)$, as shown in Eq. 12, with respect to period for different ductilities and with damping ratio $\zeta=0.05$

exceeding the index's tolerance associated to the 4 performance levels are specified as 1/43, 1/72, 1/475, and 1/970 for different performance objectives. Similarly, $\varepsilon$ associated to the four indices being exceeded can also be estimated from Fig. 10(b).

Furthermore, from Eq. (12), $B(T n)$ is defined as a function of system period, $T n$, and system ductility. It is possible to generate a $B(T n)$ spectrum. Fig. 11 shows the $B(T n)$ with respect to structure period $T n$ for different values of system ductility. Through Eq. (11), with the consideration of system characteristics, the annual probability of index tolerance being exceeded with respect to $E_{h} / m$ can be generated with respect to a specific period (Tn), as shown in Fig. 12. Since the hysteretic energy does not only depend on the input ground motion, but also the system characteristics, so the seismic hazard curve of $E_{h} / m$ has already been implemented with the structural system characteristics.

\section{DEVELOPMENT OF DAMAGE INDEX HAZARD CURVES}

In vision-2000, four performance levels (fully operational, operational, life safe and near collapse) are illustrated by written description. There is no explicit parameter to quantify these four performance levels, such as drift ratio or damage index. In this research, the seismic hazard curves, represented by Park \& Ang's damage index $(D M)$, are generated based on the discussion in the previous sections. Generally, the design level has been presented by the recurrence interval of earthquake occurrence, and the annual probability of being exceeded associated to the four performance levels are specified as $1 / 43,1 / 72$, $1 / 475,1 / 970$, respectively, as the basic objectives. In this study, performance level is determined by damage index. Through the proposed model in this research, the relationship between performance level (damage index) and design level (annual probability

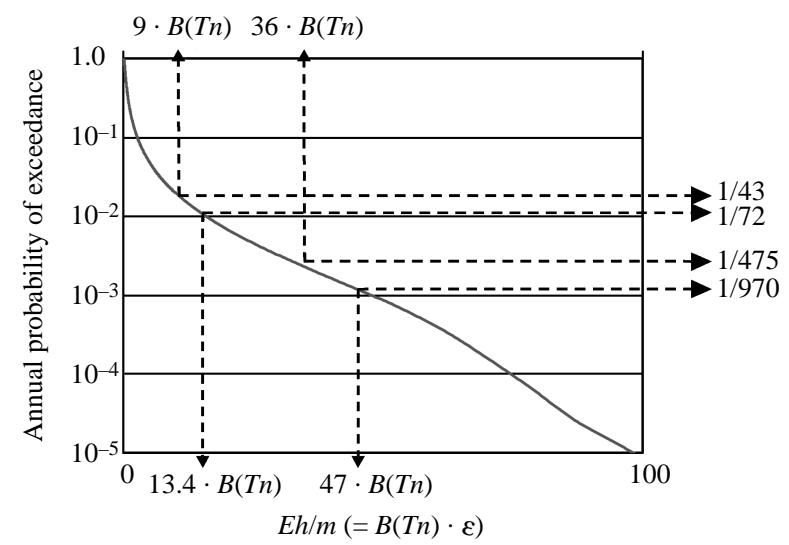

Fig. 12 Seismic hazard curve of hysteretic energy in I-Lan county for the specific period, $T n$

of tolerance being exceeded) can be established.

To simplify the equation of Park \& Ang's damage index, the Eq. (1) can be rewritten as follow:

$$
D M=\frac{\mu_{D e m}}{\mu_{C a p}}+\frac{E h_{D e m}}{E h_{C a p}}
$$

where $\mu_{D e m}$ is ductility demand, $\mu_{C a p}$ is ductility capacity, $E h_{D e m}$ is the seismic demand due to hysteretic energy and $E h_{C a p}$ is the system capacity due to hysteretic energy, defined as follows:

$$
E h_{\text {cap }}=\frac{Q_{y} \delta_{u}}{\beta}
$$

Eq. (20) can be rewritten as follows:

$$
E h_{D e m}=\left(D M-\frac{\mu_{D e m}}{\mu_{C a p}}\right) \cdot E h_{C a p}
$$

After preliminary design, the period $(T n)$ of the objective should be determined. And $B(T n)$ can be specified from $B(T)$ spectrum, as shown in Fig. 11. With the specific $D M, E h_{C a p}, \mu_{D e m}, \mu_{C a p}$ (by preliminary design), the $E h_{D e m}$ can be calculated from Eq. (22), and then, the $\varepsilon$ demand can be figured out from the following equation:

$$
\varepsilon=\left(\frac{E h_{D e m}}{m}\right) / B(T)
$$

A flow chart is also provided to present the evaluation process above, as shown in Fig. 13. As soon as $\varepsilon$ demand has been figured out, the annual probability of index tolerance being exceeded would be specified from Fig. 10(b).

As mentioned above, the damage indices associated to the four performance levels in Vision 2000 are pre-determined as $0.25,0.5,0.75,1.0$, respectively. After that, the relationship between the performance level (represented by damage index) and design level 


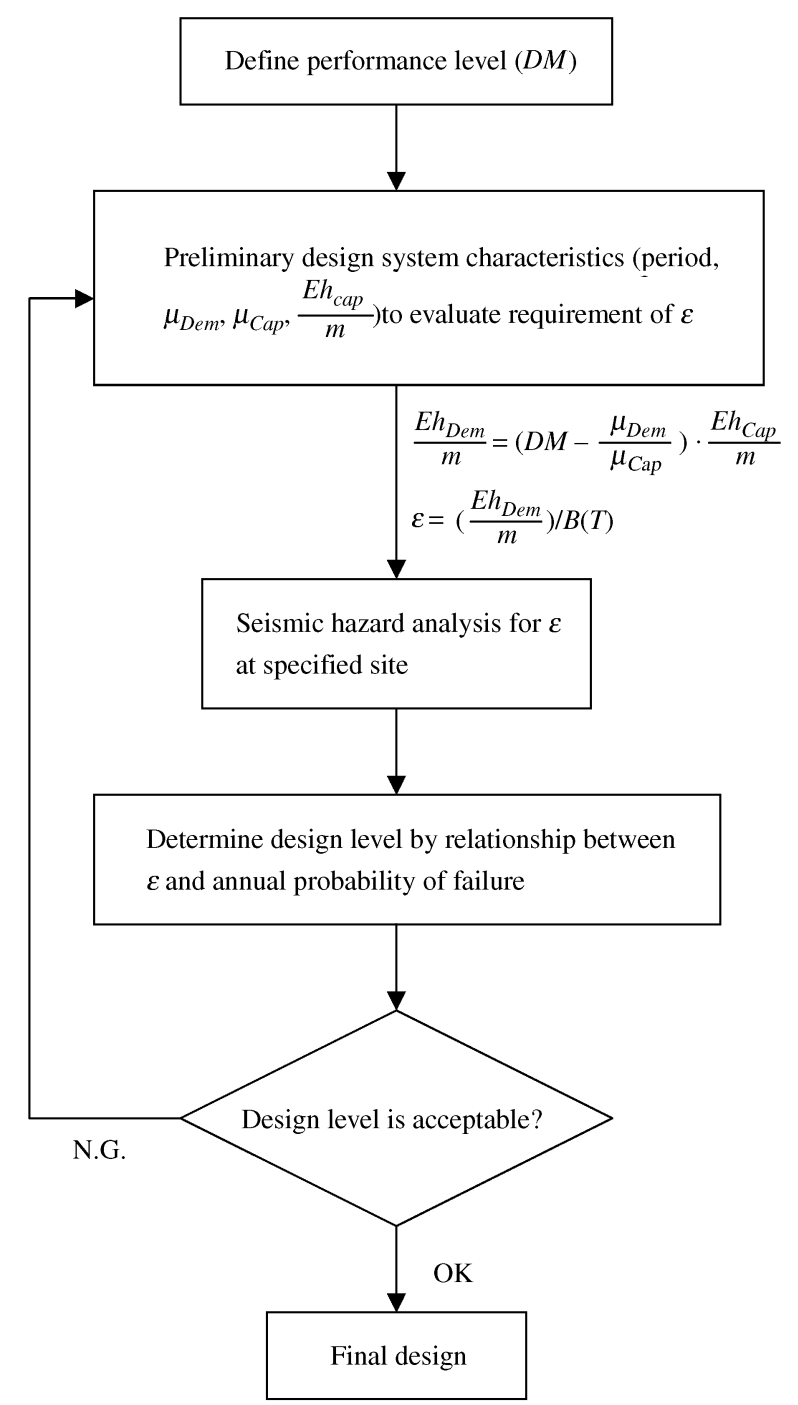

Fig. 13 Flow chart for determining design level at a specific performance level

(represented by the probability of being exceeded) will be developed, as shown in Fig. 14. In Fig. 14, the upper diagram shows the recommendation of Vision2000 and the lower figure shows the result from this study. The difference is that the Vision-2000 suggested the fixed annual probability of index tolerance being exceeded associated to the four performance levels, on the contrary, this proposed method suggested the estimated probability of being exceeded, P1, P2, P3, and $\mathrm{P} 4$ associated to four design levels. The determination of P1 P4 not only depend on seismic intensity but also on the structural system characteristics. The influences of structural characteristics lead to the annual probability of index standard being exceeded (P1 P4) not being fixed to a certain value as Vision2000 suggested $(1 / 43,1 / 72,1 / 475$, and 1/970). Therefore, from Fig. 14 one can determine the annual probability of index tolerance being exceeded for a
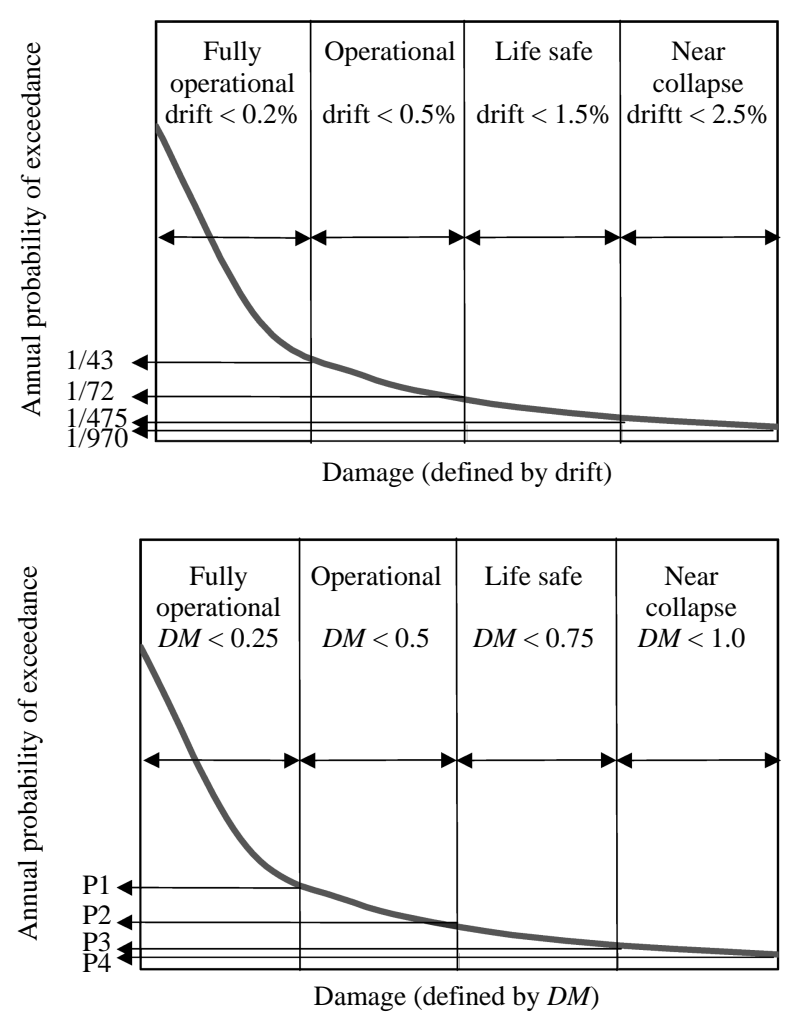

Fig. 14 Comparison of the diagrams of the performance levels (above: in terms of drift; below: in terms of Damage Index) versus design levels (in terms of annual probability of failure)

pre-determined damage situation. It provides a good reference for engineers in defining the design level corresponding to the target performance level.

\section{EXAMPLE}

For this study, I-Lan county, located in north Taiwan, was chosen as the test site. 390 ground motion data from Taiwan were chosen to generate the attenuation form, including $P G A, P G V$, and $I e$. Seismic hazard analysis for hysteretic energy was also conducted. According to the process, as shown in Fig. 13, the system characteristics (period, $\mu_{\text {Dem }}, \mu_{\text {cap }}$, $E h_{C a p}$ ) have to be designed first. $\varepsilon$ demand can be estimated from Eq. (23). Through Fig. 10(b), annual probability of index standard being inadequate can be specified with respect to $\varepsilon$ demand. Table 3 shows a basic system with single degree of freedom (whose period is defined as $T=0.75$ second, $\mu_{\text {Dem }}=2, \mu_{\text {cap }}=$ $\left.14, E h_{C a p} / m=1\left(\mathrm{~m}^{2} / \mathrm{sec}^{2}\right)\right)$, whose $\varepsilon$ and annual probability of index standard failure for various ductilities $(\mu=2,4,5,6)$ can be estimated. In this case, for period $T n=0.75 \mathrm{sec}$, the performance level (damage index) versus design level (annual probability of index standard being exceeded) can be generated, as shown in Fig. 15. The designer can use this diagram 
Table $3 B(T), \varepsilon$ and annual probability of failure for this study (for $T=0.75$ sec, $\mu_{D e m}=2, \mu_{C a p}=14$, $E h_{c a p} / m=1 \mathrm{~m}^{2} / \mathrm{sec}^{2}, \zeta=0.05$ ) in I-Lan county.

\begin{tabular}{cccccc}
\hline Ductility & & 2 & 4 & 5 & 6 \\
\hline$B(0.75)$ & & 0.46 & 0.54 & 0.52 & 0.49 \\
\hline$\varepsilon$ & $D M=0.25$ & 0.231 & - & - & - \\
& $D M=0.50$ & 0.771 & 0.391 & 0.277 & 0.146 \\
& $D M=0.75$ & 1.310 & 0.861 & 0.761 & 0.656 \\
& $D M=1.00$ & 1.849 & 1.324 & 1.245 & 1.166 \\
\hline Annual & $D M=0.25$ & 0.848 & - & - & - \\
probability & $D M=0.50$ & 0.366 & 0.63 & 0.783 & 0.961 \\
of & $D M=0.75$ & 0.218 & 0.33 & 0.371 & 0.424 \\
failure & $D M=1.00$ & 0.151 & 0.215 & 0.229 & 0.245 \\
\hline
\end{tabular}

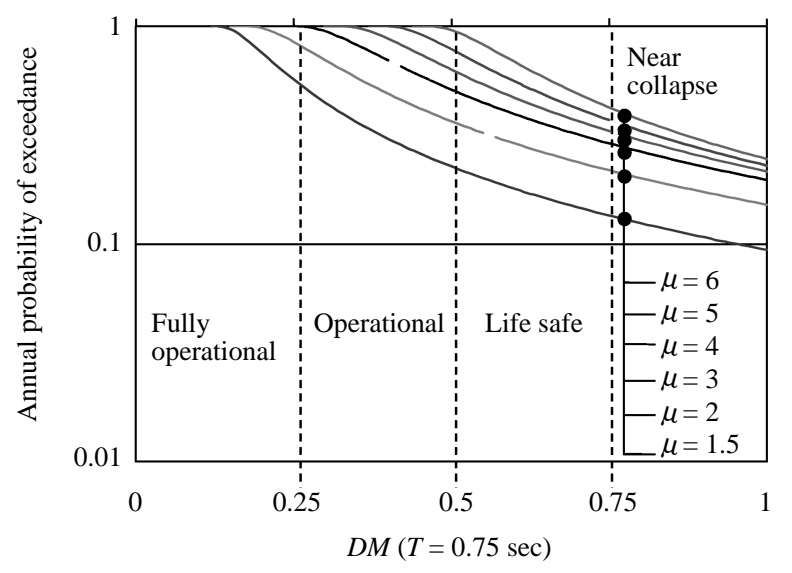

Fig. 15 Performance level versus design level diagram as the system Period $=0.75 \mathrm{sec}$ and $\zeta=0.05$

to estimate the seismic hazard associated to the requirements for the specific performance level (at fixed period $=0.75 \mathrm{sec})$. Furthermore, Fig. 16 shows the performance level (damage index) versus design level (annual probability of failure of index standard) diagram for different structural periods. The designer can take advantage of Fig. 16 to choose the period for the objective if the ductility demand has been determined previously (for example: $\mu=$ 4). The spectrum for annual probability of index standard failure at a specific performance level (fully operational, operational, life safe, or near collapse) can be plotted, as shown in Fig. 17(a) 17 (d). The designers can use these 4 diagrams to choose the structural period to meet the requirement of the design level to meet the specific performance needs.

\section{CONCLUSIONS}

The purpose of this approach is to provide information on annual index standard failure probability

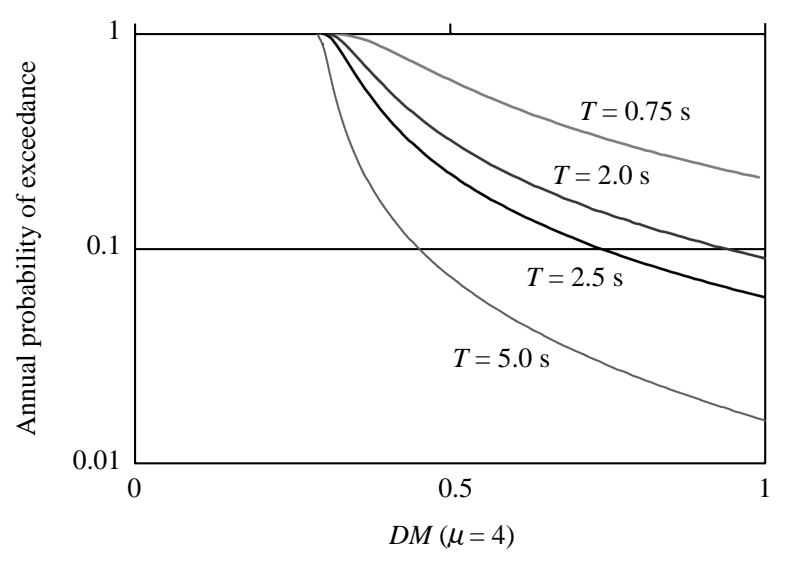

Fig. 16 Plot of annual probability of failure with respect to damage measure $(\mu=4)$ for different structural periods

among structural performance (in terms of damage index), system ductility, and structural period. Comparing our results to Vision-2000, the result of this study is helpful for designers to assess what performance a building will generate under a specific seismic hazard.

In performance based design, one of the most important meanings is to understand the performance (damage) of the structure when subjected to specific intensity of earthquake loading. This research provides the conceptual ideas of generating damage-related hazard curves, including the performance level versus design level diagrams in different system ductilities or structural periods, and the spectra of annual probability of failure for a specific performance level, etc. Designers can use those diagrams of performance level versus design level to check if the performance level of the building meets the requirements. In addition, the performance level can also be modified through choosing appropriate ductility or period of the building. 


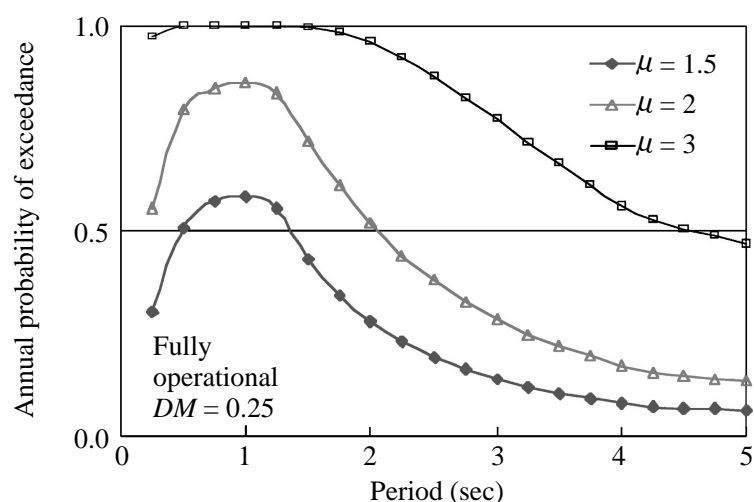

(a)

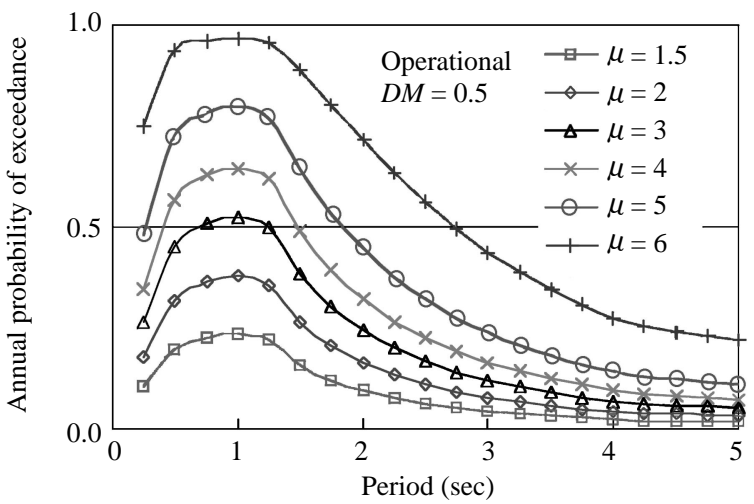

(b)

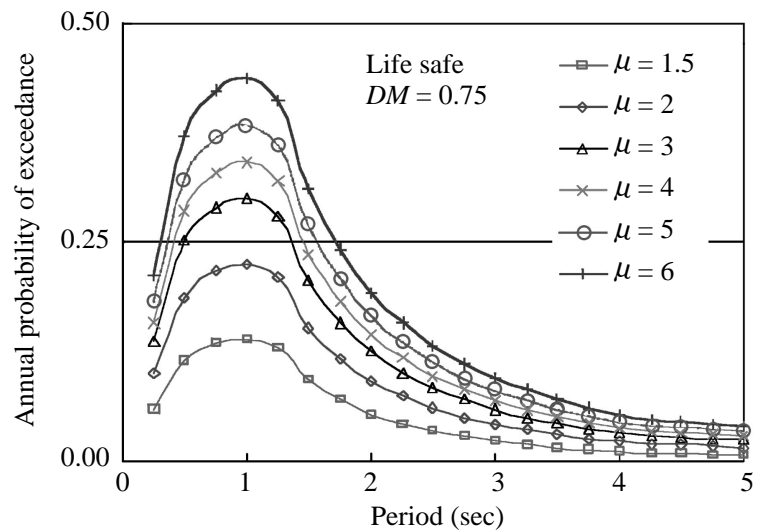

(c)

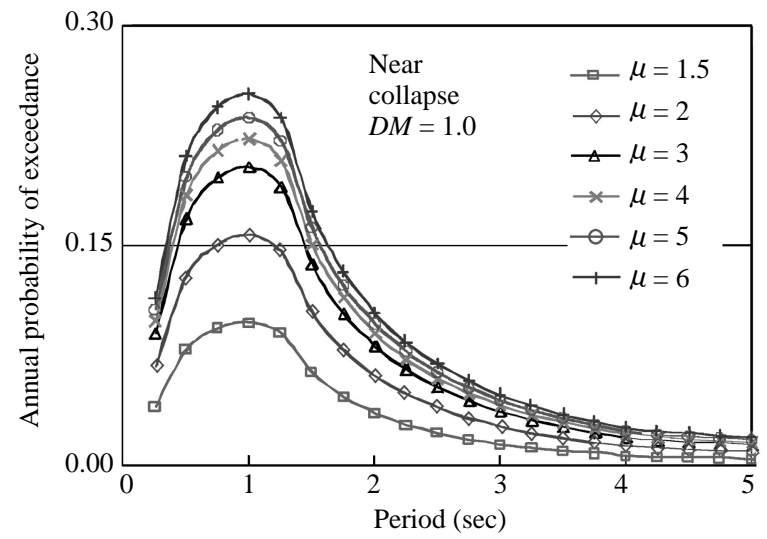

(d)

Fig. 17 (a) Plot of annual probability of failure with respect to structural period for different ductilities subject to a specific performance level (fully operational level). (b) Plot of annual probability of failure with respect to structural periods for different ductilities subject to a specific performance level (operational level). (c) Plot of annual probability of failure with respect to structural period for different ductilities subject to a specific performance level (life safe level). (d) Plot of annual probability of failure with respect to structural period for different ductilities subject to a specific performance level (Near collapse level).

\section{ACKNOWLEDGMENTS}

The authors wish to express their thanks to NSC for the support of this research under grant number NSC 91-2211-E-002-079.

\section{REFERENCES}

Campbell, K. W.,1981, "Near-Source Attenuation of Peak Horizontal Acceleration," Bulletin of the Seismological Society of America, Vol. 71, No. 6, pp. 2039-2070.

Loh, C. H., Jean W. Y., and Chung, S. T., 1999, "Seismic Hazard Analysis," Technical Report, Center for Earthquake Engineering Research, National Taiwan University, Taipei, Taiwan, R.O.C.

Miranda, E. and Ruiz-Garcia J., 2002, "Evaluation of Approximate Methods to Estimate Maximum Inelastic Displacement Demands," Earthquake Engineering and Structural Dynamics, Vol. 31, pp. 539-560.

Park, Y. J. and Ang, A. H-S., 1985, “Mechanistic Seismic
Damage Model for Reinforced Concrete," Journal of Structural Engineering, ASCE, Vol. 111, No. ST4, pp. 722-739.

Structural Engineers Association of California, 1995, Performance Based Seismic Engineering of Buildings, Sacramento, CA, USA.

Uang, C. M. ,and Bertero V. V., 1990, "Evaluation of Seismic Energy in Structures," Earthquake Engineering and Structural Dynamics, Vol. 19, pp. 77-90.

Vidic, T., Fajfar, P., and Fischinger, M., 1994a, "Consistent Inelastic Design Spectra: Strength and Displacement," Earthquake Engineering and Structural Dynamics. Vol. 23, pp. 507-521.

Vidic, T., Fajfar, P., and Fischinger, M., 1994b, "Consistent Inelastic Design Spectra: Hysteretic and Input Energy," Earthquake Engineering and Structural Dynamics, Vol. 23, pp. 523-537.

Manuscript Received: Aug. 26, 2003 Revision Received: Aug. 04, 2004 and Accepted: Sep. 23, 2004 